\title{
DAMPAK KUALITAS PELAYANAN TERHADAP KEPUASAN PASIEN BPJS DI PUSKESMAS JATILAWANG KABUPATEN BANYUMAS
}

\author{
Kusumaningtyas \\ Mahasiswa Program Studi Magister Administrasi Publik, FISIP, Universitas Jenderal Soedirman \\ Email: kstyas@gmail.com
}

\begin{abstract}
Satisfaction is a feeling that shows a person's happiness or disappointment that comes after comparing the performance (outcome) of the thinking product to the expected performance (or outcome). Quality of service and satisfaction (patient) is a unity that is difficult to separate. To realize the patients' satisfaction of BPJS at The Primary Health Service (Puskesmas) of Jatilawang Banyumas Regency as public health service owned by the government, in its development is demanded to give good service quality by increasing employee competence and also pay attention to service quality dimension itself. That are reliability, responsiveness, assurance, tangibles, and empathy. This research is a descriptive quantitative research with the cross-sectional approach which aims to know in general about how the level of patient satisfaction. Meanwhile, the specific purpose of this study to determine how much impact the quality of health services to BPJS patient satisfaction. The results showed that in general from the results of the t-test, the variable reliability (X1), responsiveness (X2), assurance (X3), tangibles (X4) and empathy (X5) partially positive and have a significant effect on patients' satisfaction of BPJS service (Y). Furthermore, the variable reliability (X1), responsiveness (X2), assurance (X3), tangibles (X4) and empathy (X5) simultaneously have a positive and significant effect on BPJS patient satisfaction (Y). Specifically, the amount of BPJS patient satisfaction at The Community Health Center of Jatilawang, Banyumas is equal to 0.992 or $99.2 \%$.
\end{abstract}

Keywords: Health service quality, Patients' satisfaction

\section{PENDAHULUAN}

Kepuasan merupakan upaya pemenuhan sesuatu agar menjadi memadai. Hal ini berarti bahwa kepuasan menjadi fungsi dari persepsi atau kesan atas kinerja dan harapan. Kepuasan atau ketidakpuasan dari konsumen adalah perasaan konsumen tentang tingkat pengalaman dari sebuah organisasi dalam mewujudkan atau menyediakan apa yang dibutuhkan oleh konsumen. Menurut Franziska Kruger (2016: 11) atas identifikasinya mengemukakan ada tiga definisi yang saling terkait pertama, kepuasan pasien adalah respon emosional secara effective maupun cognitive yang bervariasi; kedua, responnya berkaitan dengan fokus tertentu, misalnya, harapan, produk, atau pengalaman konsumsi; ketiga, responnya adalah waktu yang spesifik, misalnya setelah konsumsi dan pengalaman. Dengan menerapkan ketiga aspek kepuasan ini, peneliti memiliki kemungkinan untuk secara jelas menguraikan dan mendefinisikan kepuasan sebagai variabel penelitian.

Pelayanan kesehatan Puskesmas merupakan tombak utama untuk menciptakan kesehatan masyarakat. Dengan adanya kebijakan Jaminan Kesehatan yang dilaksanakan oleh BPJS Kesehatan menuntut puskesmas sebagai lembaga yang menajalankan Fasilitas Kesehatan 
Tingkat Pertama untuk berbenah dalam peningkatan kualitas pelayanannya. Peningkatan kualitas pelayanan yang dimaksud adalah pelayanan kesehatan yang berkualitas agar mampu mengkoordinir seluruh kebutuhan masyarakat peserta BPJS Kesehatan yang semakin hari semakin bertambah banyak jumlahnya. Pelayanan kesehatan yang berkualitas diharapkan akan mampu meningkatkan kepuasan pasien.

Puskesmas Jatilawang adalah salah satu puskesmas di Kabupaten Banyumas yang bertanggung jawab dalam upaya kesehatan tingkat pertama di Kecamatan Jatilawang. Adapun data kunjungan pasien di Puskesmas Jatilawang terdapat pada tabel berikut:

Tabel 1. Data Kunjungan Pasien Puskesmas Jatilawang Tahun 2016

NO Bulan Pasien Jumlah

\begin{tabular}{|c|c|c|c|c|c|}
\hline & & Umum & BPJS & $\begin{array}{c}\text { KBS (Kartu } \\
\text { Banyumas } \\
\text { Sehat) }\end{array}$ & \\
\hline 1 & Januari & 2569 & 2523 & 103 & 5195 \\
\hline 2 & Pebruari & 2779 & 2675 & 125 & 5579 \\
\hline 3 & Maret & 2680 & 2890 & 137 & 5707 \\
\hline 4 & April & 2641 & 2461 & 126 & 5228 \\
\hline 5 & Mei & 2400 & 2190 & 158 & 4748 \\
\hline 6 & Juni & 2341 & 1866 & 145 & 4352 \\
\hline 7 & Juli & 2280 & 1757 & 135 & 4172 \\
\hline 8 & Agustus & 2717 & 2156 & 137 & 5010 \\
\hline 9 & September & 2343 & 2061 & 137 & 4541 \\
\hline 10 & Oktober & 2289 & 2414 & 173 & 4876 \\
\hline 11 & Nopember & 2219 & 2076 & 157 & 4452 \\
\hline 12 & Desember & 2291 & 2357 & 167 & 4815 \\
\hline Jumlah & & 29549 & 27426 & 1700 & 58675 \\
\hline
\end{tabular}

Sumber: Data Puskesmas Jatilawang

Tabel di atas menjelaskan bahwa jumlah kunjungan pasien BPJS Kesehatan lebih sedikit dibandingkan jumlah pasien non BPJS Kesehatan. Hal tersebut menjelaskan bahwa kajian terhadap kualitas pelayanan kesehatan puskesmas Jatilawang masih diperlukan dalam rangka meningkatkan pelayanan kesehatan yang lebih baik dari waktu ke waktu dan yang lebih utama adalah mendukung keberhasilan pemerintah dalam rangka melaksanakan kebijakan Jaminan Kesehatan Nasional oleh BPJS Kesehatan. Dengan demikian hal menarik untuk diteliti adalah bagaimana pengaruh kualitas pelayanan kesehatan terhadap kepuasan pasien. Dalam menganalisis pengaruh kualitas pelayanann terhadap kepuasan pasien tersebut digunakan model SERVQUAL. Model tersebut digambarkan sebagai berikut:

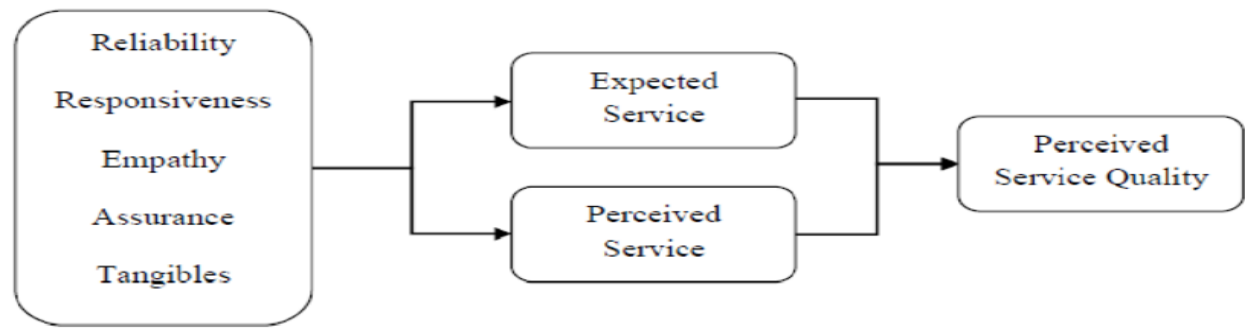

Gambar 1. Model Servqual 
Model SERQUAL berasal dari kata service quality yang dikembangkan oleh Parasuraman, et al yang terdiri dari lima dimensi kehandalan (reliability), daya tanggap (responsiveness), jaminan (assurance), bukti langsung (tangibles) dan empati (empathy).

\section{METODE PENELITIAN}

Penelitian ini termasuk dalam jenis penelitian kuantitatif deskriptif dengan menggunakan pendekatan cross-sectional. Pada studi kuantitatif deskriptif dijelaskan bahwa untuk melakukan pengamatan dengan interpretasi tepat serta termasuk penggunaan analisa statistik untuk menggambarkan secara akurat sifat-sifat dari beberapa fenomena kelompok. Selanjutnya penelitian ini menggunakan metode survei dengan mengambil sampel dari suatu populasi dan menggunakan kuesioner sebagai alat pengumpul data yang utama. Populasi dalam penelitian ini adalah seluruh pasien BPJS Puskesmas Jatilawang. Sebagai penunjang data, penelitian ini juga menggunakan observai, wawancara mendalam dan studi dokumentasi. Pelaksanaan penelitian ini pada bulan September sampai November 2017. Hipotesis dalam penelitian ini adalah a) Kualitas pelayanan kesehatan (reliability, responsiveness, assurance, tangibles, dan empathy) tidak mempunyai pengaruh terhadap kepuasan pasien BPJS Kesehatan Puskesmas Jatilawang, b) Kualitas pelayanan kesehatan (reliability, responsiveness, assurance, tangibles, dan empathy) mempunyai pengaruh terhadap kepuasan pasien BPJS Kesehatan Puskesmas Jatilawang. Definisi variabel berdasarkan variabel, indikator dan pernytaan penelitian ini akan dijelaskan pada tabel berikut:

Tabel 2. Matriks Definisi

\begin{tabular}{|c|c|c|}
\hline Variabel & Indikator & Pernyataan \\
\hline \multirow[t]{4}{*}{ Reliability } & Kecepatan & $\begin{array}{c}\text { Penerimaan pendaftaran pasien dilayani secara } \\
\text { cepat }\end{array}$ \\
\hline & Daya tanggap & Ketanggapan tenaga medis dalam membantu pasien \\
\hline & Kehandalan & $\begin{array}{l}\text { Kehandalan tenaga medis dalam memberikan } \\
\text { informasi }\end{array}$ \\
\hline & Kesiapan & Kesiapan dokter dan perawat dalam melayani pasien \\
\hline \multirow[t]{3}{*}{ Responsiveness } & Ketanggapan & Ketanggapan perawat melayani pasien \\
\hline & $\begin{array}{l}\text { Kesediaan dalam menjelasakn } \\
\text { penyakit }\end{array}$ & $\begin{array}{l}\text { Kesediaan tenaga medis dalam memberikan } \\
\text { pejelasan tentang penyakit pasien }\end{array}$ \\
\hline & Ketepatan tindakan & Kecepatan dan ketepatan tindakan tenaga medis \\
\hline \multirow[t]{3}{*}{ Assurance } & Kemampuan & $\begin{array}{l}\text { Kemampuan dokter dalam mejawab pertanyan } \\
\text { pasien dan diagnose yang akurat }\end{array}$ \\
\hline & Kelangkapan obat-obatan & Kelengkapan kesediaan obat-obatan \\
\hline & Kecekatan & Kecekatan dan kemampuan tenaga medis \\
\hline \multirow[t]{3}{*}{ Tangibles } & Kebersihan & Kebersihan, kenyamanan dan keindahan bangunan \\
\hline & Kelengkapan peralatan & Kelengkapan peralatan yang dibutuhkan pasien \\
\hline & Kerapian petugas & Kerapian penampilan tenaga medis \\
\hline \multirow[t]{3}{*}{ Empathy } & Pelayanan sesuai kebutuhan & Pemberian pelayanan yang sesuai kebutuhan pasien \\
\hline & $\begin{array}{l}\text { Kesediaan waktu untuk } \\
\text { keluhan }\end{array}$ & Penyediaan waktu untuk keluhan pasien \\
\hline & kesopanan & Kesopanan dan keramahan tenaga medis \\
\hline $\begin{array}{l}\text { Kepuasan } \\
\text { Pasien }\end{array}$ & $\begin{array}{l}\text { Kepuasan atas kesesuain } \\
\text { harapan }\end{array}$ & $\begin{array}{l}\text { Kesesuain atas produk, pelayanna dan fasilitas } \\
\text { terhadap harapan }\end{array}$ \\
\hline
\end{tabular}




\begin{tabular}{ll}
$\begin{array}{l}\text { Adanya minat berkunjung } \\
\text { kembali }\end{array}$ & Mempunyai minat untuk berkunjung kembali \\
\hline $\begin{array}{l}\text { Adanya kesediaan } \\
\text { merekomendasikan }\end{array}$ & $\begin{array}{l}\text { Kesediaan merekomendasikankepasa teman dan } \\
\text { kerabat untuk berkunjung }\end{array}$ \\
\hline $\begin{array}{l}\text { Kepuasan terhadap } \\
\text { mekanisme komplain }\end{array}$ & Ketersedian mekasnisme complain yang jelas \\
\hline $\begin{array}{l}\text { Kepuasan terhadap pelayanan } \\
\text { kesehatan }\end{array}$ & $\begin{array}{l}\text { Keseluruhan pelayanan yang diterima dan dirasakan } \\
\text { oleh pasien. }\end{array}$
\end{tabular}

\section{HASIL DAN PEMBAHASAN}

\section{Hasil Penelitian}

\section{Hubungan Reliability, Responsiveness, Assurance, Tangibles dan Empathy terhadap Kepuasan Pasien}

Dalam mengetahui hubungan antar variabel maka akan dilakukan uji korelasi dengan menggunakan Product Moment antara variabel bebas dengan variabel terikat. Berikut merupakan hasil perhitungan korelasi Product Moment antara variabel Kepuasan Pasien (Y) dengan variabel Reliability (X1), Responsiveness (X2), Assurance (X3), Tangibles (X4) dan Empathy (X5).

Tabel 3. Korelasi Antar Variabel Bebas dan Variabel Terikat

\begin{tabular}{|c|c|c|}
\hline Variabel & Koefisien Korelasi/Sig & Tingkat Hubungan/Signifikansi \\
\hline Reliability & 0,945 & $\begin{array}{c}\text { Kuat } \\
\text { Signifikansi 1\% }\end{array}$ \\
\hline Responsiveness & 0,892 & $\begin{array}{c}\text { Kuat } \\
\text { Signifikansi 1\% }\end{array}$ \\
\hline Assurance & 0,735 & $\begin{array}{c}\text { Sedang } \\
\text { Signifikansi 1\% }\end{array}$ \\
\hline Tangibles & 0,827 & $\begin{array}{c}\text { Signifikansi 1\% } \\
\text { Kuat }\end{array}$ \\
\hline Empathy & 0,836 & $\begin{array}{c}\text { Signifikansi } 1 \% \\
\text { Kuat }\end{array}$ \\
\hline
\end{tabular}

Sumber: data primer diolah 2017

Berdasarkan data di atas, hasil uji korelasi menunjukkan bahwa kelima koefisien korelasi bernilai positif. Hal tersebut terlihat dari nilai koefisien korelasi yang positif dan memiliki tingkat hubungan yang kuat untuk reliability $\left(\mathrm{X}_{1}\right)$, responsiveness $\left(\mathrm{X}_{2}\right)$, tangibles $\left(\mathrm{X}_{4}\right)$ dan empathy $\left(\mathrm{X}_{5}\right)$ Sedangkan untuk assurance $\left(\mathrm{X}_{3}\right)$ memiliki tingkat hubungan yang sedang. Selain itu, kelima variabel bebas yakni reliability $\left(\mathrm{X}_{1}\right)$, responsiveness $\left(\mathrm{X}_{2}\right)$, assurance $\left(\mathrm{X}_{3}\right)$, tangibles $\left(\mathrm{X}_{4}\right)$ dan empathy $\left(\mathrm{X}_{5}\right)$ secara bersama-sama memiliki korelasi yang sangat signifikan dengan kepuasan pasien.

\section{Pengaruh Reliability, Responsiveness, Assurance, Tangibles dan Empathy terhadap Kepuasan Pasien}

Proses regresi linier dapat dilkakukan berdasarkan hasil Asumsi Klasik dan uji korelasi product modament. Perhitungan regresi linier berganda diperoleh hasil sebagai berikut: 
Tabel 4. Korelasi antara Variabel Bebas terhadap Variabel Terikat

\begin{tabular}{lcc}
\hline & $\begin{array}{c}\text { Koefisien korelasi } \\
(\mathrm{r})\end{array}$ & $\begin{array}{c}\text { Koefisien determinan } \\
(\mathrm{R})\end{array}$ \\
\cline { 2 - 3 } $\begin{array}{l}\text { reliability }\left(\mathrm{X}_{1}\right) \text {, responsiveness }\left(\mathrm{X}_{2}\right), \\
\text { assurance }\left(\mathrm{X}_{3}\right) \text {, tangibles }\left(\mathrm{X}_{4}\right) \text {, dan }\end{array}$ & & \\
tangibles $\left(\mathrm{X}_{5}\right)$ terhadap Kepuasan $(\mathrm{Y})$ & 0,992 & 0,985 \\
\hline
\end{tabular}

Sumber: Data primer diolah, 2017

Berdasarkan hasil analisis dengan regresi linear berganda ditemukan koefisien korelasi antara variabel bebas reliability $\left(\mathrm{X}_{1}\right)$, responsiveness $\left(\mathrm{X}_{2}\right)$, assurance $\left(\mathrm{X}_{3}\right)$, tangibles $\left(\mathrm{X}_{4}\right)$, dan empathy $\left(\mathrm{X}_{5}\right)$ terhadap kepuasan $(\mathrm{Y})$ sebesar 0,992 dengan arah hubungan positif. Ini artinya terhadap hubungan yang kuat, positif dan signifikan secara bersama-sama variabel bebas terhadap variabel terikat.

Pengaruh secara bersama-sama variabel bebas terhadap variabel terikat ditujukkan oleh nilai koefisien determinan ( $\mathrm{R}$ Square) sebesar 0,985 . Hal ini berarti reliability $\left(\mathrm{X}_{1}\right)$, responsiveness $\left(\mathrm{X}_{2}\right)$, assurance $\left(\mathrm{X}_{3}\right)$, tangibles $\left(\mathrm{X}_{4}\right)$, dan empathy $\left(\mathrm{X}_{5}\right)$ mampu menjelaskan kepuasan pasien sebesar 98,5 persen, sedangkan sisanya 1,5 persen dijelaskan oleh faktor lain yang tidak diteliti.

Tabel 5. Koefisien Korelasi

\begin{tabular}{lcc}
\hline & $\mathrm{B}$ & Sig \\
\hline Konstanta & 14,553 & 0.000 \\
Reliability & .872 & 0.000 \\
Responsiveness & $1,087$. & 0.000 \\
Assurance & .517 & 0.000 \\
Tangibles &, 318 & 0,006 \\
Empathy &, 301 & 0,008 \\
\hline
\end{tabular}

Sumber: Data primer diolah, 2017

Pada tabel koefisien korelasi menunjukkan bahwa jika diuji sendiri-sendiri, reliability ternyata berpengaruh secara signifikan terhadap kepuasan karena nilai $P$ atau sig. sebesar 0,000 masih lebih kecil dari patokan yang digunakan yakni 0,050. Untuk responsiveness juga berpengaruh secara signifikan terhadap kepuasan, karena nilai $P$ atau sig. 0,000 masih lebih kecil dari nilai patokan yang digunakan yakni 0,05. Selain itu, assurance juga memiliki pengaruh yang signifikan terhadap kepuasan, karena nilai $P$ atau sig. 0,000 masih lebih kecil dari nilai patokan yang digunakan yakni 0,05 , tangibles juga berpengaruh terhadap kepuasan, karena nilai $\mathrm{p}$ atau sig 0,006 masih lebih kecil dari nilai patokan yang digunakan yakni 0,05, empathy juga berpengaruh terhadap kepuasan, karena nilai $\mathrm{p}$ atau sig 0,008 masih lebih kecil dari nilai patokan yang digunakan yakni 0,05.

\section{Pembahasan}

Pengaruh Dimensi Reliability terhadap Kepuasan Pasien BPJS di Puskesmas Jatilawang Kabupaten Banyumas

Berdasarkan hasil pengujian hipotesis, pertama ditemukan bahwa reliability berpengaruh secara positif dan signifikan terhadap kepuasan pasien. Hal ini berarti reliability 
yang dimiliki puskesmas Jatilawang Kabupaten Banyumas sangat berpengaruh terhadap kepuasan pasien BPJS Kesehatan. Hasil penelitian tersebut sekaligus mendukung penelitian terdahulu yang menemukan bahwa reliability berpengaruh terhadap kepuasan pasien.

Pelayanan yang diharapkan oleh setiap pasien adalah pelayanan yang mampu dengan mudah diberikan kepercayaan atas keandalan yang diberikan. Dengan reliability maka pasien/ pelanggan akan dapat merasakan kepuasan atas pelayanan yang diberikan. Reliability merupakan dimensi yang mampu menggerakkan tingkat kepuasan pasien. hal ini akan mampu membawa pasien untuk percaya dan akan datang kembali. Secara umum reliability memiliki pengaruh yang tinggi terhadap kepuasan pasien BPJS Kesehatan di Puskesmas Jatilawang. Semua indikator pada reliability masuk dalam kategori tinggi, hal ini berarti sebagian besar pasien mimiliki kepuasan yang sesuai dengan harapan dan sebagian kecil belum sesuai dengan yang diharapkan. Berdasarkan hasil korelasi dan regresi linier juga menunjukkan bahwa indikator dalam reliability perlu untuk selalu dipertahankan bahkan ditingkatkan lagi. Reliability yang dimiliki oleh Puskesmas Jatilawang memiliki pengaruh yang signifikan terhadap kepuasan pasien BPJS Kesehatan.

Indikator-indikator reliability yang mendukung kepuasan pasien BPJS Kesehatan di Puskesmas Jatilawang perlu untuk selalu ditingkatkan. Kecepatan penerimaan pendaftaran, keinginan tenaga medis dalam membantu pasien, kehandalan tenaga medis dalam memberikan informasi, dan kesiapan dokter serta petugas medis dalam menjalankan pelayanan. Pengaruh reliability pada Puskesmas Jatilawang dapat menjelaskan kepuasan pasien sebesar 89,3 persen, sedangkan sisanya 10,7 persen dijelaskan oleh variabel lain. Berdasarkan perhitungan tersebut reliability memiliki kategori tinggi dalam mempengaruhi kepuasan pasien BPJS Kesehatan. Indikator-indikator reliability yang mendukung peningkatan kepuasan pasien BPJS di puskesmas Jatilawang Kabupaten Banyumas sudah baik adanya.

\section{Pengaruh Dimensi Responsiveness terhadap Kepuasan Pasien BPJS di Puskesmas Jatilawang Kabupaten Banyumas}

Berdasarkan hasil pengujian hipotesis, kedua ditemukan bahwa responsiveness berpengaruh secara positif dan signifikan terhadap kepuasan pasien. Hal ini berarti responsiveness yang dimiliki puskesmas Jatilawang Kabupaten Banyumas sangat berpengaruh terhadap kepuasan pasien BPJS Kesehatan. Hasil penelitian ini mendukung penelitian terdahulu yang menemukan bahwa responsiveness berpengaruh terhadap kepuasan. Said Abusalem, John A Myers, Yousef Aljeesh (2012) menemukan bahwa responsiveness berpengaruh terhadap kepuasan pasien.

Responsiveness memiliki tingkat kepentingan yang cukup tinggi dalam memberikan kepuasan kepada pasien. Responsiveness mampu menjelaskan dan memprediksi pasien puas secara positif. Oleh karena itu, variabel ini perlu dipertahankan dan ditingkatkan secara terusmenerus untuk menjaga citra organisasi kesehatan. Excellent Service Quality telah menjadi 
harga mati yang harus diberikan perusahaan kepada pelanggan, responsiveness dianggap sebagai alat yang dapat digunakan untuk mencapai keunggulan kompetitif dan meminbulkan suatu loyalitas pelanggan. Responsiveness is willingness to help customers and provide prompt service (Saghier, Nathan, 2013).

Indikator- indikator responsiveness yang mendukung kepuasan pasien BPJS Kesehatan di Puskesmas Jatilawang harus selalu ditingkatkan. Ketanggapan perawat dala melayani pasien BPJS Kesehatan, Kesediaan tenaga medis dalam memberikan penjelasan kepada pasien BPJS Kesehatan terkait penyakit yang dialami, dan kecepatan serta ketepatan tindakan kepada pasien BPJS Kesehatan oleh tenaga medis. Pengaruh responsiveness pada Puskesmas Jatilawang dapat menjelaskan kepuasan pasien sebesar 79,5 persen, sedangkan sisanya 20,5 persen dijelaskan oleh varinbel lain. Berdarakan perhitungan tersebut responsiveness memiliki kategori sedang dalam mempengaruhi kepuasan pasien BPJS Kesehatan. Indikator- indikator responsiveness yang mendukung peningkatan kepuasan pasien BPJS di Puskesmas Jatilawang Kabupaten Banyumas sudah baik.

Responsiveness secara umum memiliki pengaruh yang sedang terhadap kepusan pasien BPJS Kesehatan di Puskesmas Jatilawang. Kondisi yang terlihat adalah Puskesmas Jatilawang tidak hanya cepat tanggap pada keluhan konsumen yang timbul, namun juga cepat tanggap menangkap perubahan yang terjadi dalam pasar, teknologi, peralatan dan perilaku konsumen. Sebab, melalui penelitian pada pasien BPJS Kesehatan di Puskesmas Jatilawang dapat digali pendapat bahwa untuk mencapai tujuan pembangunan kesehatan harus mampu meningkatkan ketanggapan oleh dokter, perawat dan tenaga medis dalam melakukan pelayanan kepada pasien.

\section{Pengaruh Dimensi Assurance terhadap Kepuasan Pasien BPJS di Puskesmas Jatilawang Kabupaten Banyumas}

Berdasarkan hasil pengujian hipotesis, ketiga ditemukan bahwa assurance berpengaruh secara positif dan signifikan terhadap kepuasan pasien. Assurance yang diberikan puskesmas Jatilawang Kabupaten Banyumas mempunyai pengaruh terhadap kepuasan pasien BPJS Kesehatan. Seema Sharma (2016) menemukan bahwa assurance berpengaruh terhadap kepuasan pasien, ia menjelaskan the average servqual perception score for assurance dimension comes to be 6.03, which is well above the 80\% perception threshold level for this dimension. Penelitian ini mendukung penelitian terdahulu yang memberikan hasil sama bahwa assurance mampu mempengaruhi kepuasan pelanggan.

Assurance mencakup komunikasi, kredibilitas, keamanan, kompetensi, pengetahuan, kemampuan, kesopanan, kemampuan dan sifat dapat dipercaya yang dimiliki para staff, bebas dari bahaya, resiko atau keragu-raguan. Tujuan dari ini adalah untuk menumbuhkan rasa percaya pelanggan kepada perusahaan. Assurance is knowledge and politeness of service 
providers and their ability to promote an atmosphere of trust and safety to the patient (Zamil, Areiqat, 2012).

Kualitas pelayanan dengan assurance diartikan sesuatu yang lebih berhubungan dengan bagaimana pelayanan diberikan kepada pasien, yang terdiri dari penyampaian informasi yang jelas, kemudahan melakukan hubungan, komunikasi yang baik, serta kecekatan petugas medis. Indikator-indikator assurance yang mendukung kepuasan pasien BPJS Kesehatan di Puskesmas Jatilawang perlu agar selalu mendapatkan perhatian. Kemampuan dokter dalam menjawab pertanyaan pasien BPJS Kesehatan secara akurat/ meyakinkan, kelengkapan terhadap kesediaan obat-obatan, kecekatan dan kemampuan tenaga medis. Pengaruh assurance pada Puskesmas Jatilawang mampu menjelasakan kepuasan pasien sebesar 54,1 sedangakn sisanya sebesar 45,9 persen dijelaskan oleh variabel lain. Perhitungan tersebut pada assurance memiliki kategori rendah dalam mempengaruhi kepuasan pasien BPJS Kesehatan. Indikatorindikator assurance yang mendukung peningkatan kepuasan pasien BPJS di Puskesmas Jatilawang Kabupaten Banyumas berada pada nilai rendah.

Secara umum assurance memiliki pengaruh yang sedang terhadap kepuasan pasien BPJS Kesehatan di Puskesmas Jatilawang. Semua indikator dalam assurance masuk katogori sedang, ini berarti assurance cukup memiliki pengaruh dalam dalam memberikan kepuasan terhadap pasien BPJS Kesehatan. Berdasarkan hasil korelasi dan regresi linier juga menunjukkan bahwa indikator dalam assurance masih perlu ditingkatkan. Assurance yang dimiliki oleh Puskesmas Jatilawang memiliki pengaruh yang signifikan terhadap kepuasan pasien BPJS Kesehatan.

\section{Pengaruh Dimensi Tangibles terhadap Kepuasan Pasien BPJS di Puskesmas Jatilawang Kabupaten Banyumas}

Berdasarkan hasil pengujian hipotesis, keempat ditemukan bahwa tangibles berpengaruh secara positif dan signifikan terhadap kepuasan pasien. dalam hal ini dapat diartikan tangibles yang diberikan puskesmas Jatilawang Kabupaten Banyumas sangat berpengaruh terhadap kepuasan pasien. Hasil penelitian ini mendukung penelitian terdahulu yang menemukan bahwa reliability berpengaruh terhadap kepuasan. The average SERVQUAL perception score for tangibility dimension comes to be 6.16, which is well above the 80\% perception threshold level for this dimension (Sharma, 2016).

Kualitas pelayanan tidak hanya meliputi bagaimana tindakan yang diberikan pihak Puskesmas terhadap pasien BPJS Kesehatan saja, namun juga meliputi fasilitas fisik, perlengkapan dan peralatan yang digunakan. Tangibility as the appearance of physical facilities, equipment, personnel, and written materials (Saghier, Nathan, 2013). Pada tangibles pasien akan merasakan pelayanan lewat fasilitas fisik yang mereka gunakan. Tangibles merupakan dimensi yang sangat kuat dalam mempengaruhi persepsi kepuasan, karena seperti contoh jika gedung bangunan tidak terawat pelanggan pun tidak akan mau datang kembali. 
Indikator- indikator yang ada pada tangibles harus selalu ditingkatkan untuk menunjang kepuasan pasien BPJS Kesehatan di Puskesmas Jatilawang. Kebersihan, kenyamanan dan keindahan bangunan; kelegkapan peralatan yang dibutuhkan oleh pasien BPJS Kesehatan; kerapian penampilan seluruh tenaga medis. Pengaruh tangibles pada Puskesmas Jatilawang dapat menjelaskan kepuasan pasien sebesar 68,4 persen, sedangkan sisanya sebesar 31,6 persen dijelaskan oleh variabel lain. Indikator- indikator tangibles yang mendukung peningkatan kepuasan pasien BPJS di Puskesmas Jatilawang Kabupaten Banyumas sudah memiliki niali cukup, namun perlu peningkatan.

Secara umum tangibles memiliki pengaruh pada tingkat yang cukup terhadap kepuasan pasien BPJS Kesehatan di Puskesmas Jatilawang. Namun, pada tangibles sebagian besar belum sesuai harapan. berdasarkan hasil korelasi dan regresi linier juga menunjukkan bahwa indikator dalam tangibles perlu ditingkatkan lagi. Tangible yang dimiliki oleh Puskesmas Jatilawang memiliki pengaruh yang signifikan terhadap kepuasan pasien BPJS Kesehatan.

\section{Pengaruh Dimensi Empathy terhadap Kepuasan Pasien BPJS di Puskesmas Jatilawang Kabupaten Banyumas}

Berdasarkan hasil pengujian hipotesis, kelima ditemukan bahwa empathy berpengaruh langsung secara positif dan signifikan terhadap kepuasan pasien. Pada penelitian ini berarti kepuasan pasien BPJS Kesehatan sangat dipengaruhi oleh empathy. Hasil penelitian ini mendukung penelitian terdahulu yang menemukan bahwa empathy berpengaruh terhadap kepuasan.

Pasien selalu memiliki harapan untuk diberikan pelayanan yang tulus dari hati, dengan penuh perhatian oleh seluruh petugas medis. Empathy means caring, individualized attention the firm provides its customers (Ribeiro, 1993). Pelayanan dengan tulus tanpa membedakan dan melihat latar belakang pasien akan pasti membawa kualitas pelayanan meningkat. Mulai dari senyum yang tulus hingga tindakan perawatan yang ikhlas akan membuat pasien merasa diperlakukan dengan baik dan tidak menutup kemungkinan untuk merasakan kepuasan.

Indikator- indikator empathy yang mendukung kepuasan pasien BPJS kesehatan di Puskesmas Jatilawang masih sangat perlu untuk ditingkatkan. Pemberian layanan oleh dokter sesuai kebutuhan pasien BPJS Kesehatan, kesediaan waktu oleh dokter dan perawat untuk menerima keluhan pasien BPJS Kesehatan, kesopanan dan keramahan tenaga medis kepada pasien BPJS kesehatan. Pengaruh empathy pada Puskesmas Jatilawang dapat menjelaskan kepuasan pasien sebesar 20,3 persen sedangkan sisanya sebesar 79,7 persen dijelaskan oleh variabel lain. Berdasarkan perhitungan tersebut empathy memiliki kategori rendah dalam mempengaruhi kepuasan pasien BPJS Kesehatan. Indikator-inrikator empathy yang mendukung peningkatan kepuasan pasien BPJS Kesehatan Banyumas cukup baik.

Secara umum empathy memiliki pengaruh yang kecil terhadap kepuasan pasien BPJS Kesehatan di Puskesmas Jatilawang. Semua indikator pada empathy masuk dalam kategori 
rendah, hal ini berarti sebagian pasien besar belum sesuai harapan. berdasarkan hasil korelsi dan regresi linier juga menunjukkan bahwa indikator dalam empathy yang dimiliki oleh Puskesmas Jatilawang memiliki pengaruh yang signifikan terhadap kepuasan pasien BPJS Kesehatan. Empathy berarti petugas medis melayani pasien dengan sopan, ramah, penuh perhatian dan memahami apa yang dibutuhkan pasien sehingga pasien merasa puas. Untuk Puskesmas Jatilawang harus berusaha meningkatkan hal tersebut guna mendapakan kepuasan dari pasien.

\section{Pengaruh Reliability, Responsiveness, Assurance, Tangibles, dan Empathy terhadap Kepuasan Pasien}

Hasil penelitian menunjukkan bahwa perhitungan persamaan linear berganda adalah $\mathrm{Y}=$ $14,553+0,872\left(X_{1}\right)+1,087\left(X_{2}\right)+0,517\left(X_{3}\right)+0,318\left(X_{4}\right)+0,301\left(X_{5}\right)$. Hasil persamaan regresi linear berganda tersebut dapat diartikan bahwa Nilai konstanta sebesar 1 penjelasan tersebut dapat diartikan bahwa jika tidak dipengaruhi oleh variabel bebas, yakni reliability $\left(\mathrm{X}_{1}\right)$, responsiveness $\left(\mathrm{X}_{2}\right)$, assurance $\left(\mathrm{X}_{3}\right)$, tangibles $\left(\mathrm{X}_{4}\right)$ dan empathy $\left(\mathrm{X}_{5}\right)$ maka kepuasan pasien $(\mathrm{Y})$ tidak akan mengalami perubahan (konstan) sebesar 14,553. $b_{1}$ (nilai koefesien regresi $X_{1}$ ) sebesar 0,872 mempunyai arti bahwa jika reliability $\left(\mathrm{X}_{1}\right)$ lebih ditingkatkan sebesar satu satuan sedangkan variabel lainnya adalah tetap (konstan) maka akan diikuti peningkatan kepuasan pasien sebesar 0,872 satuan. $b_{2}$ (nilai koefesien regresi $\mathrm{X}_{2}$ ) sebesar 1,087 mempunyai arti bahwa jika responsiveness $\left(\mathrm{X}_{2}\right)$ lebih ditingkatkan sebesar satu satuan sedangkan variabel lainnya adalah tetap (konstan) maka akan diikuti peningkatan kepuasan pasien sebesar 1,087 satuan. $b_{3}$ (nilai koefisien regresi $X_{3}$ ) sebesar 0,517 mempunyai arti jika assurance $\left(\mathrm{X}_{3}\right)$ lebih ditingkatkan sebesar satu satuan sedangkan variabel lainnya adalah tetap (konstan) maka akan diikuti peningkatan kepuasan pasien sebesar 0,517 satuan. $\mathrm{B}_{4}$ (nilai koefisien regresi $\left.\mathrm{X}_{4}\right)$ sebesar 0,318 mempunyai arti jika tangibles $\left(\mathrm{X}_{4}\right)$ lebih ditingkatkan sebesar satu satuan sedangkan variabel lainnya adalah tetap (konstan) maka akan diikuti peningkatan kepuasan pasien sebesar 0,318 satuan. $\mathrm{B}_{5}$ (nilai koefisien regresi $\mathrm{X}_{5}$ ) sebesar 0,301 mempunyai arti jika empathy $\left(\mathrm{X}_{5}\right)$ lebih ditingkatkan sebesar satu satuan sedangkan variabel lainnya adalah tetap (konstan) maka akan diikuti peningkatan kepuasan pasien sebesar 0,301 satuan. Dengan demikian kelima variabel bebas tersebut berpanggaruh secara signifikan dan posiitif terhadap variabel kepuasan pasien BPJS di Puskesmas Jatilawang Kabupaten banyumas.

\section{KESIMPULAN}

Studi ini menarik kesimpulan bahwa 1) terdapat pengaruh yang signifikan sebesar 89,3 persen antara dimensi reliability (X1) dengan kepuasan pasien BPJS di Puskesmas Jatilawang Kabupaten banyumas dengan arah positif yang berarti semakin 
baik dimensi reliability, maka baik pula kepuasan pasien BPJS di Puskesmas Jatilawang Kabupaten banyumas; 2) Terdapat pengaruh yang signifikan sebesar 79,5 persen antara dimensi responsiveness dengan kepuasan kepuasan pasien BPJS di Puskesmas Jatilawang Kabupaten banyumas dengan arah positif yang berarti semakin baik dimensi responsiveness, maka baik pula kepuasan pasien BPJS di Puskesmas Jatilawang Kabupaten banyumas; 3) Terdapat pengaruh yang signifikan sebesar 54,1 persen antara dimensi assurance dengan kepuasan pasien BPJS di Puskesmas Jatilawang Kabupaten banyumas dengan arah positif yang berarti semakin baik dimensi assurance, maka baik pula kepuasan pasien BPJS di Puskesmas Jatilawang Kabupaten banyumas; 4) Terdapat pengaruh yang signifikan sebesar 68,4 persen antara dimensi tangibles dengan kepuasan pasien BPJS di Puskesmas Jatilawang Kabupaten banyumas dengan arah positif yang berarti semakin baik dimensi tangibles, maka baik pula kepuasan pasien BPJS di Puskesmas Jatilawang Kabupaten banyumas; 5) Terdapat pengaruh yang signifikan sebesar 20,3 persen antara dimensi empathy dengan kepuasan pasien BPJS di Puskesmas Jatilawang Kabupaten banyumas dengan arah positif yang berarti semakin baik dimensi empathy, maka baik pula kepuasan pasien BPJS di Puskesmas Jatilawang Kabupaten banyumas.

\section{Saran}

Bagi puskesmas Jatilawang sebagai berikut: Dimensi responsiveness memiliki pengaruh yang paling besar terhadap kepuasan pasien BPJS. Oleh sebab itu untuk meningkatkan responsiveness, maka lebih meningkatkan lagi kesediaan tenaga medis menanggapi keluhan pasien, ketanggapan perawat melayani pasien, Kesediaan tenaga medis dalam memberikan pejelasan tentang penyakit pasien, serta kecepatan dan ketepatan tindakan tenaga medis. Dimensi reliability memiliki pengaruh yang paling besar kedua terhadap kepuasan pasien, Oleh sebab itu untuk meningkatkan reliability, maka lebih meningkatkan lagi kecepatan dalam penerimaan pendaftaran pasien, Ketanggapan tenaga medis dalam membantu pasien serta kehandalan tenaga medis dalam memberikan informasi. Pada dimensi empathy, walapun memiliki pengaruh paling rendah namun perlu adanya peningkatan dari pihak rumah sakit. Seperti penyediaan waktu bagi pasien, dan meningkatkan keramahan kepada setiap pasien.

Bagi Peneliti Selanjutnya: Bagi peneliti selanjutnya diharapkan dapat mengembangkan lebih jauh model ini dengan mempertimbangkan variabel lain yang 
masih memiliki hubungan erat dengan reliability, responsiveness, assurance, tangibles dan empathy terhadap kepuasan.

\section{DAFTAR PUSTAKA}

Alexandra Junewicz, Stuart Youngner. 2015. Patient-Satisfaction Surveys on a Scala of 0 to 10: Improving Health Care, or Leading It Astray?

Areiqat dan Zamil. 2012. The Impact of Helath Service Quality on Patients' Satisfaction over Private and Public Hospital in Jordan" A coparative. Research gate

Faisalabad, Punjab, Pakistan. Departement of Industrial Management, Government College University

Bounthavong, Mark et al. 2010. Measuring Patient Satisfaction in The Pharmacy Specialty Immunization Clinic: A Pharmacist-run Immunization Clinic at The Veterans Affairs San Diego Healthcare System

Caruana, Money, et al. 1997. Service Quality and Satisfaction- the Moderating Role of Value. Europan Journal of Marketing

Daniel, Chingang, et al. 2010. Using the SERVQUAL. Model to Assess Service Quality and Customer Satisfaction. Student Umea School of Business

David D. Dobrzykowski, Stephen K. Callaway, Mark A. Vonderembse. 2015. Examining Pathways from Innovation Orientation to Patient Satisfaction: A Relational Vies of Healthcare Delivery

Dragan Milutinovic, et al. 2012. The Patient Satisfaction with Nursing Care Quality: The Psychometric Study of the Serbian Version of PSNCQ Questionnaire

Haksik Lee, Yongki Lee, et al. 2000. The Determinants of Perceived service Quality and its Relationship with Satisfaction. Emerald Insight: Journal of Service Marketing

Jialin Liu, et al. 2012. patient Satisfaction with Electronic Medical/ Health record: a systematic review. Emerald Insight

Klee dan Thurau. 1997. The Impact of Customer Satisfaction and Relationship Quality on Customer Retentation: A Critical Rreassessment and Model Development. Psychology \& Marketing: John Wiley \& Sons, Inc.

Kruger, Franziska. 2016. The Influence of Culture and Personality on Customer Satisfaction An Empirical Analysis across Countries. United State: Springer

Lau, Mei, et al. 2013. Measuring Service Quality in the Banking Industry: a Hong kong Based Study. Contemporary Management Research

Lee, Lin. 2005. Customer Perceptions of e-Service Quality in Online Shopping.

Lourdes Marie Tajero. 2011. The Mediating Role of The Nurse-Patient Dyad Bonding in Bringing About Patient Satisfaction

Minh Nguyen, et al. 2015. Service Quality and Customer satisfaction: A Case Study of Hotel Industry in Vietnam. Research gate: Asian Social Science

Muhammad Alotaibi, et al. 2013. Patient Satisfaction with Primary Health-care Service in Kuwait

Naik, Krishna et al. 2010. Service Quality (Servqual) and its Effect on Customer Satisfaction in Retailing. European Journal of Social Sciences

Natalie Wiebe, et al. 2014. Patient Satisfaction with Care in Epilepsy: How Much Do We Know?

Nathan dan Niveen, 2013. Service Quality Dimensions and Customers' Satisfaction of Banks in Egypt. Proceedings of 20th International Business Reserch Conference

Notoarmodjo, S. 2010. Metodologi Penelitia Kesehatan. Jakarta: rineka Cipta

Omachonu dan Einspruch. 2010. Innovation in Healthcare Delivery Systems: A Conceptual Framework. The Innovation Journal; The Public-Sector Innovation Journal 
Richard Rauck, et al. 2014. Patient Satisfaction with Fentanyl Sublingual Spray in Opioid-Tolerant Patient with Breakthrough Cancer Pain

Rust dan Zahorik. 1993. Customer Satisfaction, Customer Retention, and Market Share. Journal of Retailing

Said Abusalem, John A Myers, et al. 2012. Patient Satisfaction in Home Health Care

Shannon Westin. 2011. Satisfaction with Ovarium Carcinoma Risk-Reduction Strategies Among Women at High Risk for Breast and Ovarian Carcinoma

Sharma, Seema. 2016. Using SERVQUAL to Assess the Customer Satisfaction Level: A Study of an Urban Cooperative Bank. Journal of Economics and Public Finance

Sophia Macrodimistris, et al. 2011. Measuring Patient Satisfaction Following Epilepsy Surgery

Suchanek, Petr, et al 2014. Customer Satisfaction, Product Quality and Performance of Companies. Review of Economic Perspectives

Taylor dan Baker. An Assessment of The Relationship Between Service Quality and Customer Satisfaction in the Formation of Consumers' Purchase Intentions. Journal of Retailing

Ummu Yildiz Findik, et al. 2010. Patient Satisfaction with Nursing Care and its Relationship with Patient Characteristics 